\title{
QUANTITATIVE EVOLUTION OF MAMMOGRAPHY IN COUNTIES OF GOIÁS BETWEEN 2010 AND 2013
}

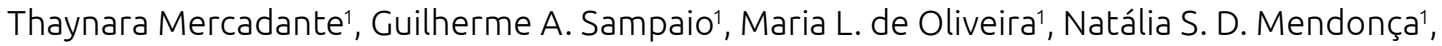
Caio Matheus Fonseca de Brito1, Jonatha Fonseca Lopes¹, Letícia de Souza Cainelli', Pedro Rodrigues Soares ${ }^{1}$

'Universidade Federal de Goiás - Goiânia (GO), Brazil.

Objectives: Analysing the quantitative evolution of mammograms in counties in the state of Goiás between the years 2010 to 2013. Methodology: this is a descriptive study using data from the Information System of breast cancer (SISMAMA). The reports reviewed were mammograms of women between 40 to 69 years in Goiás, during the years 2010 to 2013. Results: in the year 2010, the total number of tests was of 47,542. The distribution was: Goiânia with 28,903, Annapolis with 8,194 and Catalão with 1052. Right behind, the counties with the highest number of mammograms was Rio Verde, Goiatuba, Porangatu and Jataí. In 2011, the total amount of mammography pen year increased. However, there was drop in the number of tests in the city of Goiânia and increased in other cities - mainly in Catalão and Rio Verde. In 2012, the highlight was for the countie of Goiânia which increased considerably (more than 4000 examinations). In the year 2013 there was drop in the total number of mammograms performed comparing to the previous year (51,797 mammograms in 2013 and of 54,312 in 2012). In general, it was observed an increase of 4,255 mammograms carried out during the period from 2010 to 2013. Specifically, among the cities that were included in the 10 with the highest number of tests carried out in 2010, 6 remained during the period (Goiânia, Anápolis, Catalão, Rio Verde, Jataí and Aparecida de Goiânia) and four varied, with the municipalities of Goiânia, Anápolis and Catalão remained in firsts positions respectively. Conclusion: the cities with more features like Goiânia, Anápolis and Catalão have remained in top positions, showing the concentration of mammographers in the most developed cities and the difficulty of access to examination by women from smaller towns. The Brazilian Society of Mastology recommends that mammography is performed from women over 40 years annually for women with no risk factors. Among women who have access to preventive mammography, the number of deaths caused by breast cancer decreases considerably due to early diagnosis. Therefore, it is important to encourage practices such as "pink october" awareness campaigns so that it is easier to carry out the examination and the decentralization of large centers in order to reach a larger number of women occurs. 